\title{
INCLUSÃO DE PORTADORES DE NECESSIDADES EDUCACIONAIS ESPECIAIS PARA ALÉM DO ÂMBITO ESCOLAR: UMA IDEIA EM CONSTRUÇÃO NA CONTEMPORANEIDADE
}

\section{Luciana Santos de Moura ${ }^{1}$}

RESUMO: A inclusão de pessoas com necessidades educacionais especiais para além dos muros escolares é uma problemática que precisa ser enfrentada diariamente, uma vez que os espaços externos, apesar da utopia de inclusão societária, são fragmentados e direcionados a poucos sujeitos por diversos fatores, entre eles a situação financeira, a classe social e a classe racial. Sendo assim, a marginalidade é duplamente favorecida àqueles que ocupam um lugar de vulnerabilidade. O princípio da equidade vem justamente minimizar os preconceitos, trazendo como lema o tratamento diferente para sujeitos diferentes em problemas situacionais. Uma vez que, a educação inclusiva é um direito de todos os sujeitos, comprometendo-se a ofertar aprendizagem e participação sem adicionar nenhum tipo de prejuízo psicossocial, potencializando o que há de melhor no sujeito, afim de garantir um melhor desempenho e autonomia para além das instituições educacionais. Dessa forma, busca -se a emancipação do sujeito ao dar vozes àqueles que sob olhares alheios, são fardos pesados para a sociedade.

Palavras-chave: Inclusão. Exclusão. Políticas Públicas.

\section{INTRODUÇÃO}

O presente texto se propõe a discorrer sobre os prejuízos psicossociais que estão diretamente associados à marginalização desse grupo de indivíduos com necessidades educacionais especiais para além dos muros escolares e, a discriminação iminente e presente perante a sociedade que vê o diferente como algo bizarro e fora dos padrões ditos normais. E a partir desses impasses contribuírem para o enfrentamento sistemático dessa problemática tão pertinente e atual, promovendo ações de prevenção e combate contra a exclusão desses grupos e, consequentemente contribuir para a promoção da saúde psíquica e moral desses sujeitos. Fazer reflexões sistemáticas sobre a exclusão desse grupo fora dos muros escolares e mobilizar a comunidade escolar, através de campanhas e esclarecimentos sobre a importância do acolhimento daqueles que são marginalizados socialmente, apenas por ser diferente, indubitavelmente, contribuirá para a redução de preconceitos e estereótipos existentes dentro e fora dos muros escolares.

${ }^{\text {I}}$ Psicóloga pela Universidade do Estado de Minas Gerais Pedagoga pela Faculdade Estácio de Ribeirão Preto Especialista de Avaliação Psicológica e Psicodiagnostico pela IPB. E-mail: luhmourapsi@gmail.com 
E, para, além disso, permitir a autoestima das crianças e dos adolescentes com o intuito de acolhimento e aproximação dialógica para promover a espontaneidade e a confiança em seu meio social e familiar bem como o educacional e o cultural.

\section{REVISÃO DE LITERATURA}

A educação, privilégio de poucos, em um passado marcado por uma política elitizada, onde os menos favorecidos não tinham nenhum tipo de acesso, já havia a exclusão devido ao desprivilegio do saber teórico.

Partindo do pressuposto que, as práticas educacionais seriam direcionadas apenas aos mais abastados, enquanto os servos não sairiam dessa posição servil, os quais eram reprodutores da ordem social vigente. Entretanto, com a democratização da educação, depois de longos e árduos caminhos percorridos, muitas coisas mudaram, exemplo disso é a universalização do ensino.

Destarte, mesmo diante da relevante universalização do ensino, o sintoma paradoxal inclusão/exclusão persiste, onde os incluídos devem ter uma padronização de normalidade, ou seja, todos os "normais são inclusos", mas, aqueles que apresentam algum tipo de necessidade especial educacional são olhados e observados com reservas, quando não, com repulsa e terror.

Por um lado, a inclusão visa garantir os direitos daqueles que por algum motivo está às margens do lócus de inserção e do sentimento de pertencimento em relação aos pares ou de algum grupo societário. Por outro lado, somente aqueles que são adequadamente aceitos por atenderem ao padrão desenhado e idealizado pela sociedade são inclusos automaticamente aos diversos ambientes da sociedade de modo geral.

O paradoxo conflitante está posto, incluir o que já está incluído naturalmente é minimamente bizarro, pois a inclusão já está feita automaticamente. No cenário atual as lutas pela inclusão, não deveriam ser lutas, mas inserção de valores agregados ao contexto de vida daqueles que são diferentes.

A sociedade não é nem de longe homogênea, e esta afirmativa não é algo novo e muito menos arcaico, mas uma construção histórica que se intensificou muito com a globalização advinda. A multiculturalidade em parceria com a interculturalidade 
tornaram-se aspectos rotineiros, o que de fato difunde com a heterogeneidade de raças e culturas, do dito normal e do dito diferente ou anormal.

Sendo assim, é pertinente enfatizar que,

\begin{abstract}
A inclusão se baseia na ideia de que todas as pessoas devem, democraticamente, participar de forma ativa na organização da sociedade, de tal maneira que todos possam ter acesso às oportunidades de desenvolvimento sociocultural, considerando-se suas características individuais (LISITA \& SOUSA, 2003 apud RABELO \& AMARAL, 2003, p. 209).
\end{abstract}

Mas, sendo a sociedade um lócus de heterogeneidade, de várias raças e culturas, percebe-se que evidentemente os ambientes escolares enfrentarão problemas delicados. Uma vez que, não se pode barrar um discente por ser diferente ou que apresente algum tipo de necessidade educacional especial.

Mas, mesmo diante dessa problemática, a homogeneidade, então, entra em ação para dentro dos muros escolares, ou seja, o tratamento e a transmissão de saberes são iguais para todos aqueles que ali se encontram. Mas a funcionalidade desse aspecto falha de forma desastrosa aí, pois não há como transmitir saberes de forma igualitária para sujeitos que tem ritmos de aprendizagem diversos um do outro.

E para, além disso, a homogeneidade se atropela quando para dentro dos muros escolares, através de direitos garantidos pela Constituição Federal de 1988, chegam crianças e adolescentes com legítimo direito de estarem ali, são massacrados pelo despreparo e intolerância de vários profissionais da educação, entre eles, professores que não estão preparados e nem qualificados para receberem "os diferentes" que batem à porta de suas classes.

A homogeneidade cai por terra dando lugar para o despontar da heterogeneidade que brota com todas as forças vitais e com ousadia, trazendo diversas problemáticas e inovações, agregação de valores e aprendizagens. Entretanto, os docentes, em sua grande maioria ainda não estão devidamente preparados e/ou abertos nem sequer ao diálogo sobre a necessária e inevitável inclusão.

Estes sujeitos chegam, porque há uma lei que os incluem, sem a mínima perspectiva do que acontecerá dali para frente. Esta problemática atual e relevante, está no encalço diário das instituições escolares. O despreparo é gritante, a reserva dos profissionais é alarmante chegando a se tornar um caos na presença da criança ou adolescente e de seus familiares. 
Entretanto, minimamente, o governo tem aprovado portarias e leis que garantem a sua estadia ali, sem que sejam segregados ou excluídos, além de promover a garantia, de forma humanizada, de sua subjetividade e exploração de suas potencialidades.

Art. 53. A criança e o adolescente têm direito à educação, visando o pleno desenvolvimento de sua pessoa, preparo para o exercício da cidadania e qualificação para o trabalho assegurando-lhes: I - igualdade de condições para o acesso e permanência na escola; III - atendimento educacional especializado aos portadores de deficiência, preferencialmente na rede regular de ensino (ECA, Cap. IV, Lei $8069 / 90)$.

Dessa forma,

É nesse aspecto que se encontra o grande desafio da escola. A busca da homogeneidade, que confere com os propósitos do projeto econômico e político global, mas compromete o papel da escola na luta pela inclusão social dos diferentes e dos segmentos sociais com menor capacidade de enfrentamento da competitividade (...)* (BONETI, 200o, p. 238-239).

Percebe-se, assim, que o papel da escola está implicado diretamente a proporcionar a mínima garantia dos direitos quanto à estadia, o respeito às diferenças, as potencialidades de cada criança/adolescente os quais proporcionam autonomia e emancipação diariamente.

E, está implicado também ao combate dos preconceitos, estigmas, ofensas, bullying, maus tratos, dentre outras coisas que contribuem para sérios prejuízos psicossociais para cada sujeito e, consequentemente o isolamento social. O papel da escola é fundamental e imprescindível, mas, não se pode cair no reducionismo em relação à responsabilidade do papel da inclusão.

Assim, para além daqueles momentos dentro das instituições escolares, que são poucos, existem famílias e ambientes sociais onde estes sujeitos irão retornar, sem muitas vezes a garantia de continuidade, quando há, de inclusão e respeito.

Inclusão, entendida aqui como o processo de garantia do acesso imediato e contínuo da pessoa com necessidades especiais ao espaço comum da vida em sociedade, independentemente do tipo de deficiência e do grau de comprometimento apresentado. Tal compreensão traz implicações sérias, já que garantir o referido acesso vai exigir providências bi-direcionais: além das costumeiras ações de intervenção direta junto aos sujeitos com necessidades especiais, faz-se necessário desenvolver ações junto à sociedade, que deve se ajustar para a convivência na diversidade (ARANHA, 200o, p.4).

Ressalta-se que, para além de suas necessidades especiais educacionais, existe um sujeito, que é constituído de subjetividades, desejos, sonhos, alegrias e sofrimentos, entre outros diversos fatores. O acolhimento é fundamental em todos os lugares que são 
frequentados por estes, assim, não se limita apenas a escola e/ou a família, mas em todas as instâncias societárias.

Os ambientes sociais e culturais promovem, muito mais do que a própria socialização, valores éticos e morais, além de cidadania em uma convivência coletiva plena. Dessa forma, é relevante que a própria sociedade seja reeducada continuamente com o intuito de preservar eticamente o seu lugar e o lugar do outro dentro do mesmo ambiente, de maneira pacífica e acolhedora.

Entretanto, este tão desejado acolhimento, é um desafio a ser superado não só pela sociedade, mas também pelas políticas públicas. A inclusão denuncia que há uma demanda excluída que é objeto de discriminação e repulsa, seja ela social, cultural ou educacional. $\mathrm{O}$ apelo, mesmo que de forma inconsciente, da urgente inclusão por parte de todos, denuncia a complexidade da resolução uma vez que a responsabilidade não é apenas de um segmento.

$\mathrm{O}$ inconsciente coletivo diante da dualidade de um moralismo torpe e de uma lógica de violência absurda reforça e reproduz o discurso fechado e enraizado do preconceito e da intolerância frente ao diferente.

As políticas públicas ainda são deficitárias, ainda que tentem, falta muito a ser

realizado em favorecimento desse grupo. Debates e posicionamentos políticos e pedagógicos tem se arrastado já há alguns anos, e, mesmo que novas configurações no cenário venham surgindo com o passar dos anos, o final dessa problemática ainda parece longe.

Para cumprir esse papel com eficiência, objetivando um impacto social efetivo nos injustificáveis processos de exclusão social a que têm sido submetidos diversos grupos da sociedade civil, há necessidade de uma releitura das políticas públicas em andamento (MATISKEI, 2004, p.I88).

E ainda,

É necessário admitir que as políticas públicas não sejam pensadas apenas a partir de determinações jurídicas, legais, nas quais o Estado aparece como mero executor, neutro, destituído de princípios axiológicos que balizam a sua ação. Mesmo sendo as políticas públicas definidas tendo como parâmetro o bem comum de todos os segmentos sociais, deve-se perceber a dinâmica conflitiva dos diferentes interesses e forças envolvidos no tecido social (MATISKEI, 2004 apud BONETI, 200o, p.188).

Potencializar as necessidades desse grupo em situação de marginalidade só vai agravar o problema já tão explícito, onde só se reproduz a desigualdade e consequentemente o fracasso escolar, por outro lado, a potencialização de suas capacidades 
e habilidades facilitará a inserção desses sujeitos em seu lugar de direito, seja aonde for (escola, residência, parques, clubes, cinemas, dentre outros espaços sociais e culturais).

Desde tempos remotos, já existiam sujeitos com algum tipo de deficiência ou de necessidade, vindo a notar as necessidades educacionais especiais quando surgiu a educação. A partir dessa época, estes sujeitos eram excluídos ou segregados junto aos loucos, não se fazendo distinção de patologias ou limitações de cada caso.

Com o passar do tempo, a educação regular passou a segregar estes sujeitos, ou seja, tinham-se escolas apropriadas para o recebimento desse grupo que apresentava alguma deficiência ou qualquer tipo de necessidade educacional especial. Assim, havia e ainda há, mesmo com a tentativa diária da inclusão, a exclusão e marginalização desses sujeitos.

Mas, o cenário, gradativamente, vem conseguindo se reconfigurar ainda que de forma sucinta através de muitas lutas empenhadas por parte de muitos. Até que,

\begin{abstract}
Em 1994, a Declaração de Salamanca proclama que as escolas regulares com orientação inclusiva constituem os meios mais eficazes de combater atitudes discriminatórias e que alunos com necessidades educacionais especiais devem ter acesso à escola regular, tendo como princípio orientador que "as escolas deveriam acomodar todas as crianças independentemente de suas condições físicas, intelectuais, sociais, emocionais, linguísticas ou outras" (BRASIL, 2006, p.330).
\end{abstract}

Indissiocraticamente a Declaração de Salamanca passa a influenciar de forma definitiva na formulação de políticas da educação inclusiva mudando de forma considerável o cenário da educação na modalidade especial no Brasil, graças ao movimento histórico que proporciona uma visão mais ampla e consequentemente menos reducionista.

Os docentes, não rara às vezes, relatam não estarem preparados para receber discentes com algum tipo de limitação, alegando muitas vezes que as classes estão superlotadas e, por outras vezes, assumem o seu despreparo por falta capacitação ou mesmo interesse em minimamente recebe-los e saber, antes de diagnosticá-los como acontece com muita frequência nos dias atuais, do que se trata realmente e ocupar uma posição de mediador para este sujeito.

Ao recolocar a incumbência pela educação à escola e aos educadores, chega-se à conclusão de que estes têm a responsabilidade da contínua avaliação e de que a capacitação dos profissionais inicia-se numa formação sólida, mas de modo algum se esgota aí, pois a reavaliação deve ser permanente para que alcance qualidade na educação. Com isso busca-se não só a integração do aluno diferente, mas a concepção de que é a escola que deve adequar-se ao aluno e não o aluno a ela. E, 
nesse processo, os profissionais da educação estão totalmente implicados (KAFROUNI; PAN, 2oor, p.6).

Os diagnósticos dados pelos docentes aos pequenos (crianças e adolescentes), facilmente os estereotipam como doentes ou limitados. $\mathrm{O}$ cuidado e o zelo têm sido pouco utilizados pelos profissionais de uma forma geral dentro das escolas, o que desastrosamente se estende para além dos muros escolares e adentram como um câncer metastático no núcleo familiar, que é a unidade singular e original da origem de vida de cada ser.

De um lado, estes sujeitos são rotulados dentro das instituições educacionais e muitas vezes ainda segregados devido a uma "patologia" que foi diagnosticado por um docente, sem formação adequada para se fazer um diagnóstico. Importante ressaltar que o diagnóstico deverá ser feito pelo profissional adequado e licenciado para tal tarefa (médicos, fonoaudiólogos, psicólogos através do psicodiagnóstico, entre outros)

Por outro lado, o que é gravíssimo também, é que este rótulo ultrapassa os muros escolares, e mesmo, quando se já tem um diagnóstico final de alguma necessidade educacional especial, o despreparo societário com o diferente torna a vida desse sujeito muito mais difícil e inacessível.

A família, instituição primeira, tem um papel primordial em proporcionar e criar condições para esse sujeito, para sua emancipação, autonomia e participação na vida familiar, social, cultural e educacional. O que é direito deve ser exigido e, o que ainda não direito deve ser lutado e conquistado.

A inclusão de pessoas com necessidades educacionais especiais ainda é uma problemática muito presente nos dias atuais, apesar, das lutas de enfrentamento dentro e fora dos muros escolares. As políticas públicas ainda são insuficientes e falhas para atender adequadamente a demanda.

Dessa forma, estes sujeitos, os quais são dotados de subjetividades, especificidades e individualidades tornam-se um peso para a sociedade em geral. É um tema polêmico, ao se levar em consideração a carta magna do Estado Brasileiro, quando nos garante que somos todos iguais perante a lei.

Art.5 - Todos são iguais perante a lei, sem distinção de qualquer natureza, garantindo-se aos brasileiros e aos estrangeiros residentes no País a inviolabilidade do direito à vida, à liberdade, à igualdade, à segurança e à propriedade... (CF, 1988, Art. $\left.5^{\circ}\right)$. 
Entretanto, esta garantia nem sempre está presente em nosso meio social, educacional, acadêmico entre outros, pois a promoção do bem-estar parece estar voltada somente para alguns, ditos normais, cidadãos. Assim, há exclusão automática da outra parte da moeda. A superação da lógica da exclusão dentro das escolas evidencia-se na confrontação e resolução das práticas discriminatórias e na criação de alternativas para se alcançar a erradicação ou minimização de situações constrangedoras e segregadoras. Contudo, para além dos muros escolares ainda há vários obstáculos para serem superados. Obstáculos estes, em segmentos diversos, que necessariamente precisam ser cautelosamente observados para que haja uma intervenção eficaz e diretiva. Como já exposto anteriormente, as políticas públicas ainda são evasivas e deficientes em se tratando dessa problemática, mas não se pode reduzir e direcionar a responsabilidade apenas para um segmento, pois, todos de alguma forma são responsáveis pela inclusão. A família multifacetada, é necessário enfatizar aqui que hoje a dinâmica familiar mudou e muito a sua face, precisa ser o alicerce desses sujeitos.

O lócus familiar é indubitavelmente as primícias de todo desenvolvimento da criança, é neste lugar que os valores são formados e fortalecidos. A aceitação ou rejeição são codificados e muitas vezes enraizados. Os feixes de palavras são atravessados de maneira positiva ou negativa na vida do sujeito, levando-o a ser protagonista e construtor ativo de sua própria história ou ser assujeitado aos estigmas e preconceitos familiar, social e cultural.

O mito familiar implicará decisivamente naquilo em que o sujeito se tornará perante a sociedade, que não raras às vezes massacra o sujeito reduzindo-o ao que ele angariou em sua trajetória de vida. A lógica do capitalismo, entre outras coisas, alterou de forma espantosa os valores sociais, econômicos, familiares, culturais entre outros.

Entretanto, o acolhimento deve partir do próprio seio familiar, onde o princípio da equidade deve ser presente diariamente. Deve-se procurar nestes sujeitos aquilo que ele tem de melhor, suas qualidades e potenciais, minimizando dessa forma a focalização de suas dificuldades, ou seja, não o reduzindo às suas necessidades especiais. A valorização individual do sujeito tende a equilibrar o ambiente em que o mesmo está inserido, e, a imparcialidade no tratamento e julgamento garante a equidade. Contudo, este ambiente não cai no reducionismo familiar, mas se amplia para todos os lugares de direito do 
cidadão. Direitos, estes, já garantido pela Carta Magna e já exposto no texto anteriormente. Portanto, não é algo bizarro para os ditos “normais” ou um direito inacessível para uma população tão rica em heterogeneidade quanto a do século XXI. A integração da diversidade desses sujeitos deve ser pautada no respeito e no entendimento que as diferenças são riquezas peculiares às quais muito tem para se aprender e para se ensinar. Garantir este direito é um ato enobrecedor da alma e da mente, entretanto, faz-se necessá rio enfatizar que garantir não é ter pena do diferente, mas garantir àquilo que já é de direito de cada sujeito de forma autônoma, sem que o preconceito fale mais alto. Segundo Martín (1995), a integração dos alunos com necessidades especiais é uma responsabilidade que abrange toda a sociedade. Dessa forma, as intervenções não se pautam apenas em boas intenções, mas se baseia em objetivos e atuações de formas concretas. No ambiente social, onde se pode citar o parquinho, o cinema, os jogos e brincadeiras em geral, este mesmo sujeito deve ser tratado de maneira que ele sinta acolhido e não visto como o diferente, o “doente" . O estigma direcionado a este sujeito gera sofrimento e exclusão não contribuindo em nada para o desenvolvimento sua autonomia e emancipação social.

A estigmatização sofrida por esses indivíduos pode gerar reações diferenciadas na família, que incluem a vergonha pela geração daquele membro com deficiência, a dificuldade de relatar o ocorrido à família extensa, vizinhança e amigos e um consequente isolamento social, uma vez que a família seria estigmatizada por contaminação (WANDERER, 2012 apud BRITO\&DESSEN, 1999; GLAT, 2004, p. 65).

A valorização das diferenças, pois em suas particularidades os sujeitos são todos diferentes, juntamente com a acessibilidade mediante derrubadas de diversas barreiras entre elas as dos preconceitos (notadamente a maior e mais segregadora existente), as físicas, as de comunicação, de estigmas e de informações obscuras e imprecisas, contribuirão sem dúvida para a minimização das necessidades e anseios daqueles que necessitam.

A abordagem complexa não nega a ordem social, ao contrário, orienta a reflexão sobre a mesma, mas não como sinônimo de uniformidade e monolitismo, mas como integração da diversidade, portanto, uma ordem social não cristalizada e em constante configuração e conexão entre pessoas diferentes, entre o eu e a alteridade. Uma "crioulidade" em processo (SAWAIA, 2008, p.12).

É sabido que a diversidade faz parte do dia a dia de todos os seres humanos. Não há exceção. Esta conexão existe desde os tempos remotos, sendo necessária a existência de 
uma forma de linguagem para se comunicarem e se entenderem. E, assim, acontece nos dias atuais, em que a linguagem, seja ela como for (surdos-mudos, libras, visuais, verbais e não verbais entre outras) está presente a todo o momento garantindo as relações do eu com o outro.

A alteridade que é a capacidade de se colocar no lugar do outro, em qualquer tipo de situação, é algo que todos, sem exceção devem procurar desenvolver e aperfeiçoar. Uma vez que as relações interpessoais são complexas e cheias de problematizações as quais implicarão empatia e sensibilidade por parte do interlocutor que recebe a mensagem e que participa dela ativamente.

Sem a alteridade por parte daqueles que são considerados normais e consequentemente não marginalizados por uma sociedade tão massacradora da subjetividade, comportamentos desafiadores surgirão em seus mais diversos contextos e situações propostas.

A convocação preliminar da alteridade e do respeito é exatamente para minimizar ou erradicar os eventos que levam ao aparecimento destes comportamentos que desafiam tal ordem do contexto.

Assim, é relevante entender que:

As mudanças no comportamento de uma criança que ocorrem em diferentes contextos indicam que seu comportamento é influenciado ou controlado por eventos no ambiente. Observando-a atentamente em outros contextos, podemos em geral identificar acontecimentos ambientais específicos que estão associados ao comportamento adequado e acontecimentos ambientais específicos que estão associados ao comportamento desafiador (STAINBACK, 1999 apud WACKER et al, 1999, p.369).

Os prejuízos psicossociais a que os sujeitos com necessidades educacionais especiais estão expostos e muitas vezes são submetidos é altamente perturbadora e fragmentária tanto no âmbito pessoal quanto social. A alimentação do fluxo da exclusão e do preconceito só reproduz e fortalece a noção de incompletude e incapacidade desses sujeitos. A alienação societária é um câncer que se alastra em todos os níveis, é algo nocivo e bizarro.

O isolamento familiar, social e escolar é, inquestionavelmente, o maior prejuízo que o sujeito com necessidades educacionais especiais é submetido. É uma problemática delicada no âmbito psicossocial, uma vez que a vulnerabilidade psicológica a que estão 
expostos enfraquecerá o seu desenvolvimento sócio cognitivo devido o empobrecimento das trocas afetivas e experienciais.

Por um lado, as lacunas, que se desenvolvem nesse empobrecimento de trocas, se cristalizam e toda a vida do sujeito fica seriamente comprometida. Portanto, a desconstrução da segregação e da exclusão, historicamente conhecida, se faz necessária para a consequentemente construção e fortalecimento da inclusão em seus diversos âmbitos.

Por outro lado, a qualidade das trocas interpessoais com os seus pares no meio social, familiar, educacional e cultural tendenciosamente contribuem de forma positiva para a inserção assertiva em seus diversos meios.

\section{CONSIDERAÇÕES FINAIS}

Não se pretende esgotar o assunto sobre tal problemática ou apresentar uma visão paternalista sobre o tema exposto. Mas trazer à tona a discussão tão atual e pertinente em nossa sociedade, a qual está imersa na lógica do capitalismo e da globalização com os seus recorrentes problemas.

O narcisismo imperativo, o culto ao corpo, a vaidade ilógica, os meios de produção, a tecnologia e a ciência têm provocado uma cegueira global assustadora. Dessa maneira, a subjetividade tem lutado para sobreviver a este caos aterrorizante e a caminho da cronificação.

O pensar em si mesmo tem confiscado o olhar para o outro de maneira pacificadora, assim, quando o olhar é direcionado ao outro geralmente é para subjugar valores além de promover e fortalecer estigmas e preconceitos.

Em vista dos argumentos apresentados, o perfeccionismo tem dirigido olhares de repulsa ao que por "falha do destino" apresenta-se imperfeito, levando o sujeito ao distanciamento e a não identificação daquele que é diferente e que está fora do circulo dos "perfeitos iguais". O que leva a uma situação extremamente cruel e desafiadora que é excludente e nociva.

O tema discutido ao longo do texto é fruto de debates e estudos no decorrer do processo histórico que decorre e incorre da diversidade humana. O padrão estipulado por normalidade banaliza e exclui o direito humano de ser diferente. Há o esquecimento de 
que o sujeito é inteiro e igual como qualquer outro sujeito, e que a pluralidade agrega abertura de horizontes e produção de sujeitos fora do padrão de normalidade imposta pela sociedade.

A imposição de normalidade pela sociedade capitalista é nociva a diversidade de sujeitos existente no planeta. A regra é clara, o sujeito é valorizado pelo o que possui seja em bens materiais ou posições sociais. Ou tem ou não tem, ou é ou não é. Assim, se o sujeito é dotado da normalidade delimitada, imposta e aceita de forma societária, este recebe os aplausos e reconhecimento de sujeito de direitos. Caso contrário, ficarão as margens que excluem e distanciam das benesses societárias.

A desinstitucionalização da segregação e exclusão daqueles que necessitam garante o acesso ao convívio social, educacional, cultural e familiar, mas para isso aconteça é necessário a tomada de consciência e a mobilidade política e social. E não só a aceitação da diversidade por parte da sociedade, mas o engajamento por mudanças diárias em todos os contextos promovendo a aceitação de que todos têm direitos a valores e a democracias.

O posicionamento de todos os atores envolvidos faz toda a diferença, uma vez que provoca e convoca cada sujeito a uma reflexão crítica sobre o cenário atual e suas 276 dificuldades reais. Reaviva a necessidade de uma articulação intersetorial democrática e dinâmica o que certamente gera o despertar de uma prática pedagógica mais eficiente e a participação e mobilização social, cultural, educacional e familiar na prática da inclusão.

Indubitavelmente a inclusão daqueles que possuem necessidades educacionais especiais é algo minimamente desafiador. Dessa forma, o desenvolvimento de projetos sociais, culturais e educacionais em parceria com órgãos responsáveis por cada área será de grande valia para o acesso e o ingresso daquilo que já é de direito de cada cidadão com ou sem algum tipo de prejuízo psicossocial decorrente de algum agravo patológico.

O fortalecimento familiar por meio dos vários serviços existentes e a reeducação societária agregarão valores positivos ante o entendimento e acolhimento dos marginalizados apenas por serem diferentes.

Necessidades básicas inevitavelmente se esbarrarão no dia a dia daqueles que necessitam, portanto, avidamente precisam ser resolvidos por aqueles que ocupam o lugar de "sujeito perfeito". Aquele nomeado, pela sociedade capitalista e nociva, de sujeito de 
direitos e de gozo pleno. Aquele que ocupa o lugar do imediatismo e da intolerância simbólica e real.

Necessariamente se faz a compreensão a partir de uma educação contínua desde a mais tenra idade no meio familiar, instituição primeira, sobre os valores que contribuem para o crescimento, emancipação e socialização do sujeito. É fundamental, em meio a esta sociedade vive um caos sem precedente, a desconstrução de crenças e possível enraizamento de valores rasos e sem nexo baseados no narcisismo, individualismo e egoísmo.

Aos profissionais educadores são incumbidos o olhar diferenciado para aqueles que necessitam, não um olhar de pena ou de aversão, mas um olhar que busca a potencialidade individual do educando que permita o levar a emancipação e autonomia. A família o princípio da equidade e o respeito tão necessário e pouco articulado dentro da dinâmica familiar.

A sociedade, de uma maneira geral, o desenvolvimento da alteridade em relação ao outro, a quebra de obstáculos físicos e sociais em relação ao outro. As políticas públicas e sociais o provimento e o desenvolvimento de leis, portarias e ementas que minimizem e fortaleçam o lugar de direito de cada um desses sujeitos. Ao espaço cultural a oportunidade aberta para se expressar a arte por diversos meios.

Dignamente não se limita a estes espaços a luta por direitos para aqueles que possuem necessidades educacionais especiais para além dos muros escolares. Mas o compromisso firmado por todos os setores garantirá eficazmente a democratização por direitos e deveres por parte dos excluídos apenas por serem diferentes.

Infere-se, portanto, que toda criança e adolescente é única, é especial e diferente e todas, sem exceção, tem direitos universais garantidos para o seu desenvolvimento pleno de cidadão que visa a autonomia singular e a emancipação frente à sociedade.

\section{REFERÊNCIAS}

ARANHA, Maria Salete Fábio. Inclusão social e municipalização. Educação especial: temas atuais, p. $\mathrm{I}^{-9}$, 2000 .

BONETI, Lindomar Wessler. Educação, Exclusão e Cidadania. Ijuí, RGS: Unijui, 2000. 
BRASIL. Constituição da República Federativa do Brasil. Brasília, 1988. Disponível em < file:///C:/Users/cce/Downloads/constituicao_federal_35ed.pdf > Acesso em: I6 set. 2017.

BRASIL. Declaração de Salamanca e linha de ação sobre necessidades educativas especiais. Disponível em < http://portal.mec.gov.br/seesp/arquivos/pdf/revinclusao5.pdf > Acesso em: 14 agost. 2017.

KAFROUNI, Roberta Mastrantonio; DE SOUZA PAN, Miriam Aparecida Graciano. A inclusão de alunos com necessidades educativas especiais e os impasses frente à capacitação dos profissionais da educação básica: um estudo de caso. Interação em Psicologia, v. 5, n. I, 200I.

Lei $\mathrm{n}^{\mathrm{o}}$ 8069/9o- Estatuto da Criança e do Adolescente. Disponível em<http://portal.mec.gov.br/secretaria-de-educacao-especial-sp-598129159/legislacao > Acesso em: 23 set.2017

MARTÍN, Elena; MARCHESI, A. Da terminologia do distúrbio às necessidades educacionais especiais. Disponível em < file://C:/Users/cce/Downloads/I+Cap.+1+$+\mathrm{Da}+$ Terminologia + do+Disturbio + as + Necessidades + Especiais\%20(I).pdf $>$ Acesso em: 09 jul. 2017 .

MATISKEI, Angelina Carmela Romão Mattar. Políticas públicas de inclusão educacional: desafios e perspectivas. Educar em Revista [online] 2004, (Nenhum mês) : Disponível em: $<$ http://www.redalyc.org/articulo.oa?id=155017766oro $>$ ISSN oio4-406o. Acesso em o9 jul. 2017

Políticas educacionais, práticas escolares e alternativas de inclusão escolar/ \{organizadoras: Lisita, Verbena Moreira S. de S./ Sousa, Luciana Freire E. C. P.\}. - Rio de Janeiro: DP\&A, 2003.

SAWAIA, Bader. As artimanhas da exclusão: análise psicossocial e ética da desigualdade social/ Bader Sawaia (org). - 8 ed - Petrópolis, RJ: Vozes, 2008.

STAINBACK, Susan, STAINBACK, William. Inclusão: um guia para educadores/Susan Stainback; tradução Magda França Lopes. - Porto Alegre: Artmed, 1999. 456p.;23cm.

WANDERER, Aline. Violência intrafamiliar contra pessoas com deficiência: discutindo vulnerabilidade, exclusão social $e$ as contribuições da psicologia. Disponível em< http://www.repositorio.unb.br/bitstream/10482/12363/I/2012_AlineW anderer.pdf > Acesso em 13/o8/2017 